\title{
Review
}

\section{Cardiovascular Vulnerability to COVID-19 in Cancer Survivors}

\section{Beshay N. Zordoky *}

Department of Experimental and Clinical Pharmacology, University of Minnesota College of Pharmacy, Minnesota 55455

* Correspondence: zordo001@umn.edu; Tel.: 1-612-625-6499 (BNZ)

Abstract: Coronavirus disease 2019 (COVID-19) has been declared a global pandemic by the World Health Organization on March 11, 2020. COVID-19 is caused by the Severe Acute Respiratory Syndrome Coronavirus-2 (SARS-Cov-2). Although primarily a respiratory disease, cardiovascular complications of COVID-19 have been increasingly recognized. In addition, higher fatality has been reported in COVID-19 patients with underlying cardiovascular diseases. Cancer survivors have a considerably increased risk for premature cardiovascular diseases, mainly due to cardiotoxic cancer treatments. Therefore, it is foreseeable that cancer survivors will be more vulnerable to cardiovascular complications caused by COVID-19. In this review, three scenarios for increased cardiovascular complications of COVID-19 in cancer patients are proposed. In the first scenario, cardiotoxic cancer treatment and COVID-19 synergize to exacerbate direct myocardial damage. In the second scenario, cardiotoxic cancer treatment leads to a reduced cardiac reserve in cancer survivors, making them more vulnerable to COVID-19 in a "two-hit" model. The third scenario suggests that several shared risk factors may aggravate cardiovascular complications caused by both cancer treatment and COVID-19. Taken together, cancer survivors may be more vulnerable to cardiovascular complications when challenged by the COVID-19, and special cardiovascular care should be given to these patients. 
Keywords: COVID-19; Cancer Survivors; Cardiovascular

\section{Introduction.}

Coronavirus disease 2019 (COVID-19) has been declared a global pandemic by the World Health Organization (WHO) on March 11, 2020. As of April 6th, 2020, there were more than 1,200,000 confirmed cases worldwide and more than 330,000 confirmed cases in the United States alone. The number of fatalities has been increasing to surpass 67,000 worldwide and 8,900 in the Unites States (WHO and CDC websites, accessed on April $6^{\text {th }}$, 2020). COVID-19 is caused by the Severe Acute Respiratory Syndrome Coronavirus-2 (SARS-CoV-2) which is believed to be originated in bats, and moved to an intermediate host then to humans [1].

SARS-CoV-2 is transmitted primarily via respiratory droplets from both symptomatic and asymptomatic patients with a median incubation time of 4-5 days. The most reported symptoms are fever and dry cough with less frequent incidence of rhinorrhea and gastro-intestinal symptoms. The case fatality rate has been estimated to be $3.4 \%$ worldwide and $1.5 \%$ in USA [2]. Although the case fatality rate has differed significantly, a common theme is that fatality increases markedly with increasing age [3]. In addition, the case fatality rate is significantly higher in patients with other comorbidities than in healthy patients [4]. Cardiovascular disease is a common comorbidity among COVID-19 patients and higher fatality has been reported in COVID-19 patients with underlying cardiovascular disease $[5,6]$. 
The interplay between COVID-19 and cardiovascular disease is multi-faceted. First, Angiotensin Converting Enzyme-2 (ACE2), a key enzyme in the Renin Angiotensin Aldosterone System, has been recognized as a receptor to SARS-CoV-2 [7,8]. Second, COVID-19 may compromise the cardiovascular function secondary to a systemic cytokine storm [9]. Third, COVID-19 has been shown to cause direct cardiac injury [6,10]. Even though the COVID-19 is a rapidly evolving situation, several studies, commentaries, and reviews have covered this intricate relationship between COVID-19 and the cardiovascular system [11-14]. Therefore, this review will focus on COVID-19 in cancer survivors as a very special population that may be more vulnerable to cardiovascular complications.

Cancer-related survival has significantly increased in the last two decades thanks to advanced diagnosis and treatment, leading to more than 15.5 million cancer survivors in the United States [15-18]. Unfortunately, cancer survivors suffer from multitude of adverse health conditions [19-21], with a considerably increased risk for premature cardiovascular diseases [22-24]. For instance, childhood cancer survivors have an estimated 15 times higher risk of heart failure than their siblings who did not have cancer [25]. The increased risk for cardiovascular complications in cancer survivors is mainly attributed to cardiotoxic cancer treatments, particularly in breast and childhood cancer survivors $[26,27]$. Nearly $50 \%$ of pediatric cancer patients receive anthracyclines such as doxorubicin (DOX), which are known to cause cardiotoxicity [28]. Other cancer treatments may cause varying degrees of cardiotoxicity (reviewed in $[29,30]$ ). Radiation therapy can also lead to cardiovascular complications including coronary artery disease, cardiomyopathy, and myocardial fibrosis [31,32]. Cancer survivors are at increased risk for morbidity and 
mortality from infections and infection-related complications [33,34]. Indeed, influenza-induced exacerbation of pre-existing cardiovascular diseases is more common among high-risk populations, including cancer survivors [35]. Taken together, it is foreseeable that cancer survivors will be more vulnerable to cardiovascular complications caused by COVID-19. Those survivors who had been treated with cardiotoxic cancer treatments would be at the greatest risk. Therefore, the current review will briefly summarize the most commonly used cardiotoxic cancer treatments and the proposed mechanisms for their cardiotoxic effects. Then, three scenarios of increased cardiovascular vulnerability to COVID-19 in cancer survivors will be proposed.

\section{Cardiotoxic Cancer Treatment:}

The most common cardiotoxic cancer treatments are anthracyclines. Anthracyclines (e.g. doxorubicin; Adriamycin ${ }^{\circledR}$ ) are chemotherapeutic agents commonly used to treat pediatric hematologic malignancies. Unfortunately, the clinical utility of these effective agents is limited by their well-known cardiotoxic effects that can progress to end-stage heart failure [36]. Anthracyclines cause both acute and chronic cardiotoxic effects in pediatric cancer patients; however, lower anthracycline doses used in the recent treatment protocols have decreased the incidence of severe cardiovascular complications $[37,38]$. Nevertheless, subclinical cardiotoxicity occurs in those who receive even low doses of anthracyclines [39-41]. The mechanisms of anthracycline-induced cardiotoxicity include oxidative stress [42], apoptotic and necrotic cell death [43,44], cellular senescence [45-47], mitochondrial dysfunction [48], inflammation [49], and altered myocardial energy 
metabolism [50-52]. In addition to cardiotoxicity, anthracyclines are associated with endothelial dysfunction and vascular injury [53-56].

Other cardiotoxic cancer treatments include tyrosine kinase inhibitors, trastuzumab, immune check point inhibitors, cyclophosphamide, and cisplatin (reviewed in $[29,30]$ ). Sunitinib, a tyrosine kinase inhibitor, has been shown to cause heart failure in up to $8 \%$ and hypertension in up to $50 \%$ of cancer patients [57]. The proposed mechanism of sunitinib-induced cardiotoxicity is the inhibition of off-target kinases [58-60]. Trastuzumab is an epidermal growth factor receptor-2 (HER-2) monoclonal antibody that has been shown to be cardiotoxic in breast cancer patients [61]. Importantly, trastuzumab has been shown to augment anthracycline-induced cardiotoxicity [62]. Novel immune check point inhibitors have also been associated with increased risk of myocarditis [63]. Although less frequent at low doses, cyclophosphamide-induced symptomatic cardiotoxicity occurs in $5-28 \%$ of patients treated with high doses [64,65]. Cyclophosphamide-induced cardiotoxicity may be mediated by increased oxidative and nitrosative stress [66]. Cisplatin-induced cardiotoxicity has been shown to be caused by oxidative stress, mitochondrial dysfunction, increased endoplasmic reticulum stress, and apoptosis $[67,68]$.

Radiation therapy has also been shown to cause several cardiovascular adverse effects, including: pericarditis, pericardial fibrosis, myocardial fibrosis, coronary artery disease, and microvascular damage (reviewed in [69]). Similar to anthracyclines, radiation-induced cardiovascular toxicity is mediated by oxidative stress [70,71], apoptotic cell death [72], inflammation [73,74], and cellular senescence [75]. 


\section{Scenarios for increased cardiovascular complications of COVID-19 in cancer survivors:}

Cardiovascular complications of COVID-19 has been increasingly recognized [11-14,76]. Cancer survivors who had been treated with cardiotoxic treatments are at a potentially higher risk for cardiovascular complications than the general population when challenged by COVID-19. Herein, three possible scenarios for this potential increased risk will be discussed.

\section{1- Exacerbated myocardial damage:}

Myocardial damage, evidenced by elevated cardiac biomarkers, has been observed in $7.2 \%$ of patients in a study of 138 hospitalized COVID-19 patients in Wuhan, China [77]. The National Health Commission of China has estimated that $12 \%$ of patients without previous cardiovascular disease had elevated troponin levels or cardiac arrest during hospitalization [78]. The rise in cardiac markers has generally tracked the increase in inflammatory markers such as interleukin-6 [79], suggesting that myocardial injury may be secondary to a cytokine storm [76]. On the other hand, there are reports of patients presenting with primarily cardiac symptoms that may be due to viral myocarditis [80] or stress cardiomyopathy [76]. Unfortunately, higher rates of heart failure and acute cardiac injury were observed in fatal COVID-19 cases as compared to those who survive [79]. It is important to note that the SARS-CoV-2 receptor, ACE2, is highly expressed in the heart and can lead to ACE2-dependent myocardial infection [8]. Thus, COVID-19-mediated myocardial injury may exacerbate cancer treatment-induced latent cardiotoxicity in cancer survivors. 


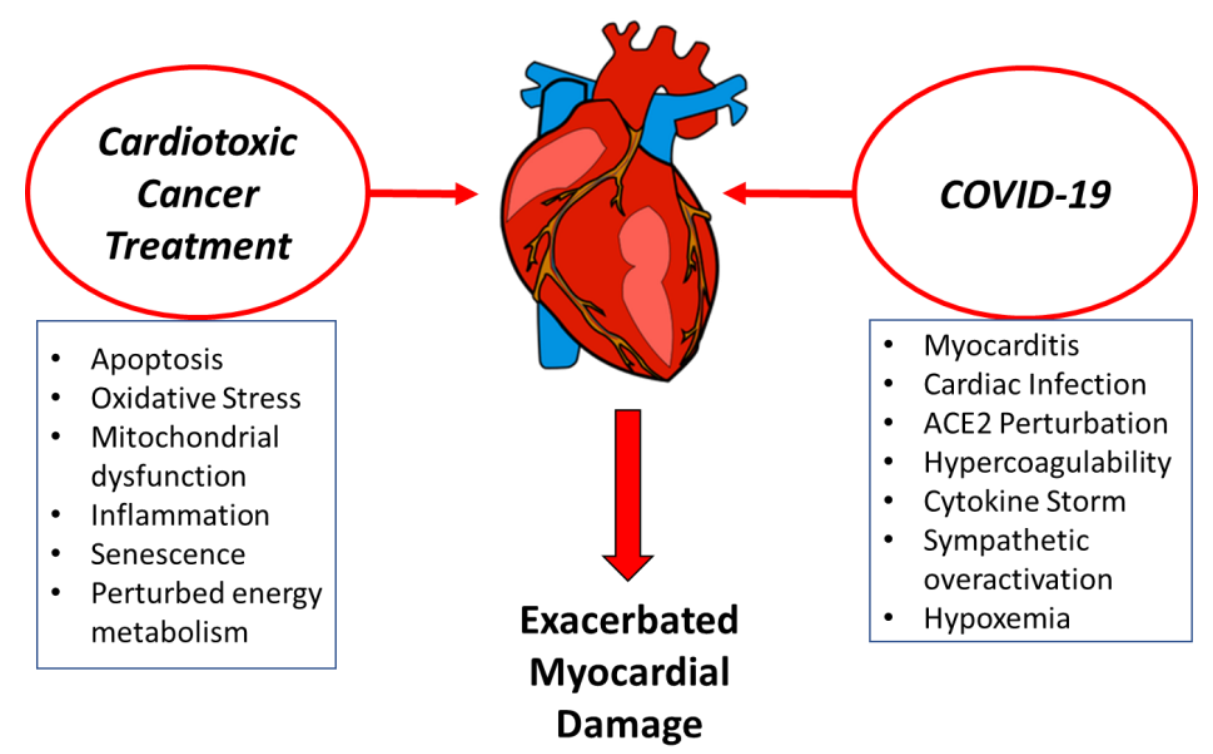

Figure 1. Exacerbated Myocardial Damage by COVID-19 in Cancer Survivors. Cardiotoxic cancer treatment and COVID-19 may synergize to exacerbate myocardial damage through a variety of mechanisms.

\section{2- Reduced cardiac reserve:}

Although the incidence of severe cardiac dysfunction and heart failure has been declining in cancer survivors due to the use of lower doses of anthracyclines in modern protocols. Anthracycline-induced subclinical cardiac dysfunction still affects up to $65 \%$ of DOX-treated pediatric cancer patients $[15,41]$. It has been suggested that anthracycline-treated childhood cancer survivors have lower cardiac reserve as compared to control subjects [24]. The subclinical cardiotoxicity and reduced cardiac reserve predispose anthracycline-treated survivors to other cardiovascular risk factors later in life in a "two-hit" manner [81]. Childhood cancer survivors have been shown to be a higher risk of cardiovascular complications when challenged by other stressors in their adult life. For instance, female survivors who had been treated with cardiotoxic therapy were more 
vulnerable to pregnancy-associated cardiovascular complications when compared to the general population [82-84]. Preclinical studies have also demonstrated that mice treated with doxorubicin at a young age were more vulnerable to cardiovascular complications when challenged by myocardial infarction [85] and hypertension [86] in their adult life. It is obvious that COVID-19 represents a stressful condition characterized by cytokine storm, sympathetic stimulation, acute respiratory distress syndrome, hypoxemia, and hypercoagulability [14]. High cardiac reserve in healthy individuals may be sufficient to overcome these challenges; however, the prognosis may be much worse in patients with reduced cardiac reserve, such as cancer survivors.

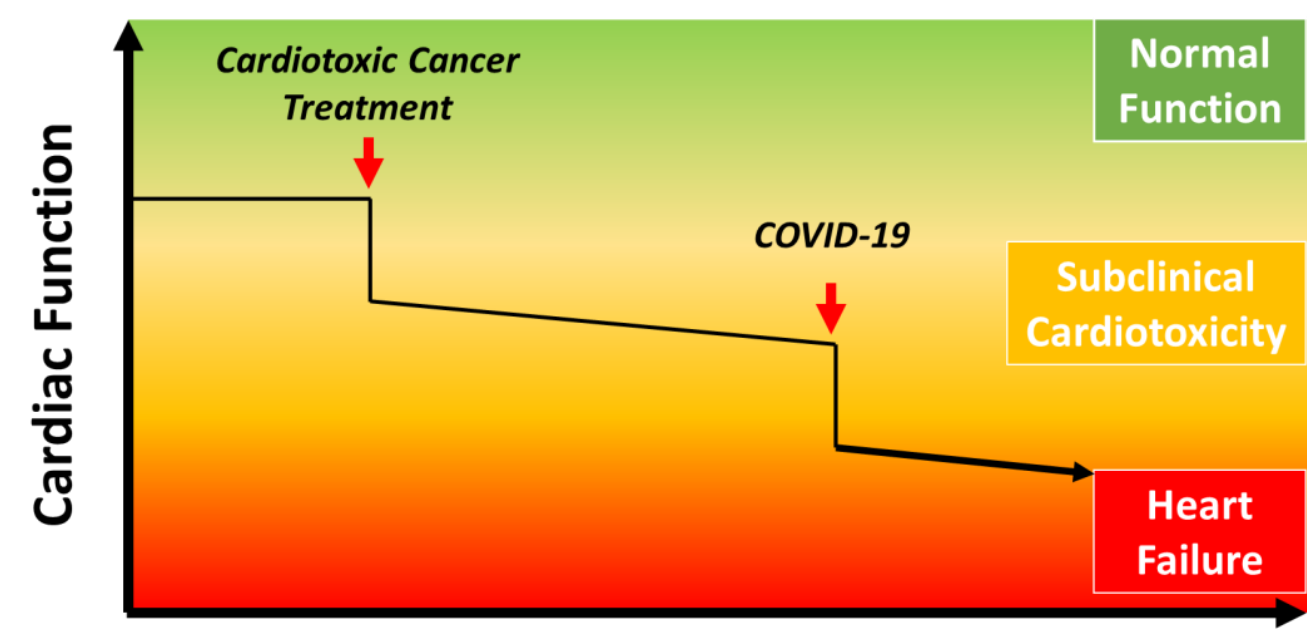

Figure 2. A "two-hit" model for exacerbated cardiac dysfunction due to COVID-19 in cancer survivors. Cardiotoxic cancer treatment causes latent subclinical cardiotoxicity in cancer survivors. A subsequent challenge by COVID-19 will further deteriorate the cardiac function leading to severe cardiac dysfunction and heart failure.

\section{3- Increased cardiovascular risk factors:}

There are several risk factors that are common between COVID-19 and cancer treatment-induced cardiotoxicity. These shared risk factors may increase the risk of 
cardiovascular complications of COVID-19 in cancer survivors who had been treated with cardiotoxic agents.

a) Hypertension: Hypertension was reported in $12.8 \%$ of a series of 44,672 confirmed COVID-19 patients in China. The case-fatality rate was $6 \%$ in hypertensive patients, while the overall case-fatality rate was $2.3 \%$ in this study [14]. Other studies have reported hypertension in $15-31 \%$ of COVID-19 hospitalized patients [77,87]. Hypertension was associated with a nearly 2.5-fold significantly increased risk of severe COVID-19 disease [88]. Intriguingly, hypertension is the most significant cardiovascular risk factor for all adverse cardiac events, including heart failure and cardiac death, in anthracycline-treated childhood cancer survivors with a 12 times higher risk for heart failure in hypertensive than in normotensive anthracycline-treated survivors [81].

b) Aging: Higher fatality rate and more severe complications of COVID-19 have been associated with advanced age [3]. Senolytics and other anti-aging drugs have been proposed for the treatment or prevention of corona virus infection [89]. Importantly, several clinical studies have demonstrated that cancer survivors show systemic signs of premature aging [19,90-92], which may put them at a greater risk for COVID-19 severe complications and even fatality. Recent publications demonstrated that DOX lead to the accumulation of senescent cells and clearance of senescent cells after DOX exposure mitigated DOX-induced cardiotoxicity [45-47]. Other pediatric cancer treatments such as radiation therapy also cause senescence [93] and lead to cardiovascular and other health complications [94]. Natural aging has been shown to predispose experimental animals to 
worse outcomes when subjected to different cardiovascular challenges such as hypertension [95] and myocardial infarction [96].

c) Psychosocial Stress: Heightened psychosocial stress [97-99], posttraumatic stress disorder, and depression have been reported in COVID-19 survivors [100,101]. Results of correlation analysis indicated that economic effects, and effects on daily life, as well as delays in academic activities, were positively associated with anxiety symptoms [102]. Headline stress disorder has also been reported during the outbreak of COVID-19 [103]. Psychosocial stress is a significant cardiovascular risk factor [104-107] and an enormous burden in up to $63 \%$ of cancer survivors [108-112]. Observational studies demonstrate that psychosocial stress is associated with higher rates of cardiovascular complications in cancer survivors [113-116]. Therefore, the increased rates of psychological disorders among COVID-19 patients and among the general population during the COVID-19 pandemic may exacerbate cardiovascular complications in cancer survivors.

d) Obesity and metabolic syndrome: School closure due to COVID-19 pandemic will likely double out-of-school time this year for many US kids; thus exacerbating the risk factors for weight gain associated with summer recess [117]. Obesity has been suggested as a risk factor for higher mortality in COVID-19 patients [118]. Obesity has both been shown to be prevalent among cancer survivors $[119,120]$, and to be a risk factor for cardiovascular disease in cancer survivors [121]. The increased risk for obesity is more prevalent in the general population during the COVID-19 pandemic, increasing the risk of cardiovascular diseases in general. 


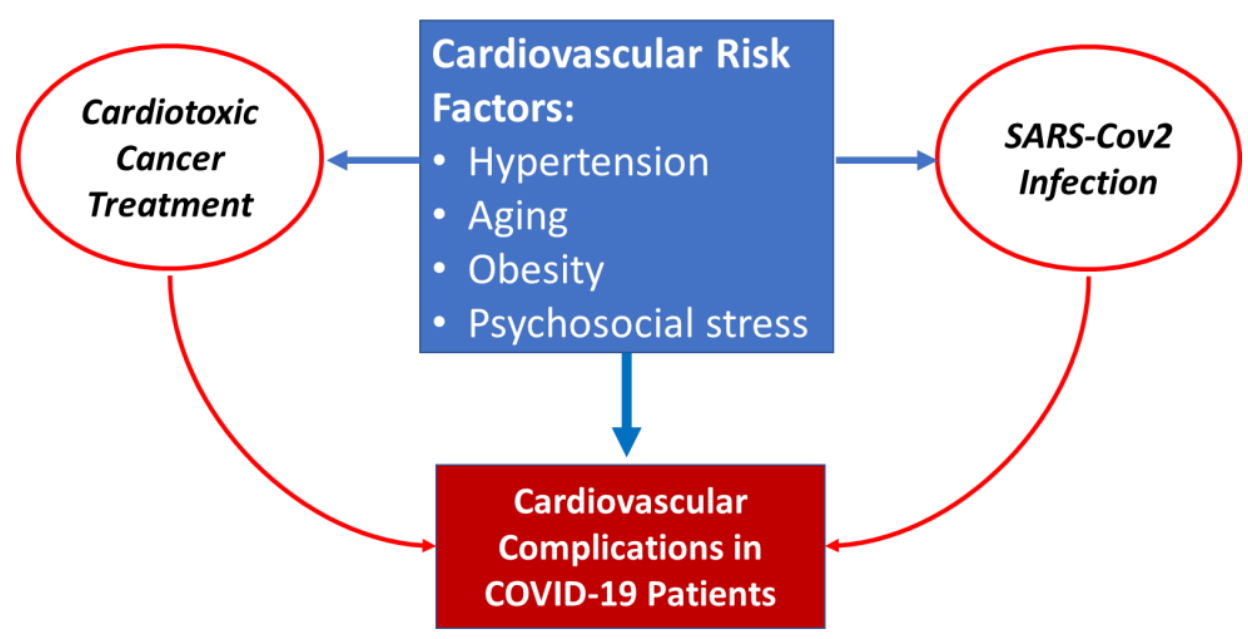

Figure 3. Cardiovascular risk factors exacerbate cardiovascular complications of COVID-19 in cancer survivors. Several risk factors may exacerbate both COVID-19 and cancer treatment-induced cardiovascular complications.

\section{Conclusions:}

COVID-19 represents an unprecedented challenge to the health care system all over the world. Although primarily a respiratory condition, COVID-19 has caused severe cardiovascular complications that are associated with higher fatality. Cancer survivors who have been treated with cardiotoxic cancer therapies may be at higher risk for severe cardiovascular complications. Therefore, special cardiovascular care should be given to cancer survivors challenged by the COVID-19. 
Funding: B.N.Z. is supported by a research grant from the St. Baldrick's Foundation for Childhood Cancer (Award ID 638335), an institutional research grant from the American Cancer Society (Award \#129819-IRG-16-189-58-IRG91), and by the National Institutes of Health's National Center for Advancing Translational Sciences, grant UL1TR002494. The content is solely the responsibility of the authors and does not necessarily represent the official views of the National Institutes of Health's National Center for Advancing Translational Sciences.

Conflicts of Interest: The author declares no conflict of interest. The funders had no role in in the writing of the manuscript, or in the decision to publish. 


\section{References:}

1. Andersen, K.G.; Rambaut, A.; Lipkin, W.I.; Holmes, E.C.; Garry, R.F. The proximal origin of SARS-CoV-2. Nature Medicine 2020, 10.1038/s41591-020-0820-9, doi:10.1038/s41591-020-0820-9.

2. Jamil, S.; Mark, N.; Carlos, G.; Dela Cruz, C.S.; Gross, J.E.; Pasnick, S. Diagnosis and Management of COVID-19 Disease. Am J Respir Crit Care Med 2020, 10.1164/rccm.2020C1, doi:10.1164/rccm.2020C1.

3. Le Couteur, D.G.; Anderson, R.M.; Newman, A.B. COVID-19 is a disease of older people. J Gerontol A Biol Sci Med Sci 2020, 10.1093/gerona/glaa077, doi:10.1093/gerona/glaa077.

4. Guan, W.J.; Liang, W.H.; Zhao, Y.; Liang, H.R.; Chen, Z.S.; Li, Y.M.; Liu, X.Q.; Chen, R.C.; Tang, C.L.; Wang, T., et al. Comorbidity and its impact on 1590 patients with Covid-19 in China: A Nationwide Analysis. Eur Respir J 2020, 10.1183/13993003.00547-2020, doi:10.1183/13993003.00547-2020.

5. Bonow, R.O.; Fonarow, G.C.; O'Gara, P.T.; Yancy, C.W. Association of Coronavirus Disease 2019 (COVID-19) With Myocardial Injury and Mortality. JAMA Cardiol 2020, 10.1001/jamacardio.2020.1105, doi:10.1001/jamacardio.2020.1105.

6. Shi, S.; Qin, M.; Shen, B.; Cai, Y.; Liu, T.; Yang, F.; Gong, W.; Liu, X.; Liang, J.; Zhao, Q., et al. Association of Cardiac Injury With Mortality in Hospitalized Patients With COVID-19 in Wuhan, China. JAMA Cardiol 2020, 10.1001/jamacardio.2020.0950, doi:10.1001/jamacardio.2020.0950.

7. South, A.M.; Diz, D.; Chappell, M.C. COVID-19, ACE2 and the Cardiovascular Consequences. Am J Physiol Heart Circ Physiol 2020, 10.1152/ajpheart.00217.2020, doi:10.1152/ajpheart.00217.2020.

8. Chen, L.; Li, X.; Chen, M.; Feng, Y.; Xiong, C. The ACE2 expression in human heart indicates new potential mechanism of heart injury among patients infected with SARS-CoV-2. Cardiovasc Res 2020, 10.1093/cvr/cvaa078, doi:10.1093/cvr/cvaa078.

9. Zhang, C.; Wu, Z.; Li, J.W.; Zhao, H.; Wang, G.Q. The cytokine release syndrome (CRS) of severe COVID-19 and Interleukin-6 receptor (IL-6R) antagonist Tocilizumab may be the key to reduce the mortality. Int J Antimicrob Agents 2020, 10.1016/j.ijantimicag.2020.105954, 105954, doi:10.1016/j.ijantimicag.2020.105954.

10. Han, H.; Xie, L.; Liu, R.; Yang, J.; Liu, F.; Wu, K.; Chen, L.; Hou, W.; Feng, Y.; Zhu, C. Analysis of heart injury laboratory parameters in 273 COVID-19 patients in one hospital in Wuhan, China. J Med Virol 2020, 10.1002/jmv.25809, doi:10.1002/jmv.25809.

11. Driggin, E.; Madhavan, M.V.; Bikdeli, B.; Chuich, T.; Laracy, J.; Bondi-Zoccai, G.; Brown, T.S.; Nigoghossian, C.; Zidar, D.A.; Haythe, J., et al. Cardiovascular Considerations for Patients, Health Care Workers, and Health Systems During the Coronavirus Disease 2019 (COVID-19) 
Pandemic. J Am Coll Cardiol 2020, 10.1016/j.jacc.2020.03.031, doi:10.1016/j.jacc.2020.03.031.

12. Li, B.; Yang, J.; Zhao, F.; Zhi, L.; Wang, X.; Liu, L.; Bi, Z.; Zhao, Y. Prevalence and impact of cardiovascular metabolic diseases on COVID-19 in China. Clin Res Cardiol 2020, 10.1007/s00392-020-01626-9, doi:10.1007/s00392-020-01626-9.

13. Guo, T.; Fan, Y.; Chen, M.; Wu, X.; Zhang, L.; He, T.; Wang, H.; Wan, J.; Wang, X.; Lu, Z. Cardiovascular Implications of Fatal Outcomes of Patients With Coronavirus Disease 2019 (COVID-19). JAMA Cardiol 2020, 10.1001/jamacardio.2020.1017, doi:10.1001/jamacardio.2020.1017.

14. Madjid, M.; Safavi-Naeini, P.; Solomon, S.D.; Vardeny, O. Potential Effects of Coronaviruses on the Cardiovascular System: A Review. JAMA Cardiol 2020, 10.1001/jamacardio.2020.1286, doi:10.1001/jamacardio.2020.1286.

15. Lipshultz, S.E.; Diamond, M.B.; Franco, V.I.; Aggarwal, S.; Leger, K.; Santos, M.V.; Sallan, S.E.; Chow, E.J. Managing chemotherapy-related cardiotoxicity in survivors of childhood cancers. Paediatr Drugs 2014, 16, 373-389, doi:10.1007/s40272-014-0085-1.

16. Lipshultz, S.E.; Sambatakos, P.; Maguire, M.; Karnik, R.; Ross, S.W.; Franco, V.I.; Miller, T.L. Cardiotoxicity and cardioprotection in childhood cancer. Acta Haematol 2014, 132, 391-399, doi:000360238 [pii]

$10.1159 / 000360238$.

17. Torre, L.A.; Bray, F.; Siegel, R.L.; Ferlay, J.; Lortet-Tieulent, J.; Jemal, A. Global cancer statistics, 2012. CA Cancer J Clin 2015, 65, 87-108, doi:10.3322/caac.21262.

18. Miller, K.D.; Siegel, R.L.; Lin, C.C.; Mariotto, A.B.; Kramer, J.L.; Rowland, J.H.; Stein, K.D.; Alteri, R.; Jemal, A. Cancer treatment and survivorship statistics, 2016. CA Cancer J Clin 2016, 66, 271-289, doi:10.3322/caac.21349.

19. Ariffin, H.; Azanan, M.S.; Abd Ghafar, S.S.; Oh, L.; Lau, K.H.;

Thirunavakarasu, T.; Sedan, A.; Ibrahim, K.; Chan, A.; Chin, T.F., et al. Young adult survivors of childhood acute lymphoblastic leukemia show evidence of chronic inflammation and cellular aging. Cancer 2017, 123, 4207-4214, doi:10.1002/cncr.30857.

20. Ness, K.K.; Armstrong, G.T.; Kundu, M.; Wilson, C.L.; Tchkonia, T.; Kirkland, J.L. Frailty in childhood cancer survivors. Cancer 2015, 121, 1540-1547, doi:10.1002/cncr.29211.

21. Blaauwbroek, R.; Stant, A.D.; Groenier, K.H.; Kamps, W.A.; Meyboom, B.; Postma, A. Health-related quality of life and adverse late effects in adult (very) long-term childhood cancer survivors. Eur J Cancer 2007, 43, 122-130, doi:S0959-8049(06)00684-8 [pii]

10.1016/j.ejca.2006.08.003.

22. Faber, J.; Wingerter, A.; Neu, M.A.; Henninger, N.; Eckerle, S.; Munzel, T.; Lackner, K.J.; Beutel, M.E.; Blettner, M.; Rathmann, W., et al. Burden of cardiovascular risk factors and cardiovascular disease in childhood cancer 
survivors: data from the German CVSS-study. Eur Heart J 2018, 39, 1555-1562, doi:10.1093/eurheartj/ehy026.

23. Bansal, N.; Blanco, J.G.; Sharma, U.C.; Pokharel, S.; Shisler, S.; Lipshultz, S.E. Cardiovascular diseases in survivors of childhood cancer. Cancer Metastasis Rev 2020, 39, 55-68, doi:10.1007/s10555-020-09859-w.

24. Foulkes, S.; Claessen, G.; Howden, E.J.; Daly, R.M.; Fraser, S.F.; La Gerche, A. The Utility of Cardiac Reserve for the Early Detection of Cancer Treatment-Related Cardiac Dysfunction: A Comprehensive Overview. Front Cardiovasc Med 2020, 7, 32, doi:10.3389/fcvm.2020.00032.

25. Oeffinger, K.C.; Mertens, A.C.; Sklar, C.A.; Kawashima, T.; Hudson, M.M.; Meadows, A.T.; Friedman, D.L.; Marina, N.; Hobbie, W.; Kadan-Lottick, N.S., et al. Chronic health conditions in adult survivors of childhood cancer. N Engl J Med 2006, 355, 1572-1582, doi:10.1056/NEJMsa060185.

26. Yeh, E.T.; Bickford, C.L. Cardiovascular complications of cancer therapy: incidence, pathogenesis, diagnosis, and management. J Am Coll Cardiol 2009, 53, 2231-2247, doi:10.1016/j.jacc.2009.02.050.

27. Jones, L.W.; Haykowsky, M.J.; Swartz, J.J.; Douglas, P.S.; Mackey, J.R. Early breast cancer therapy and cardiovascular injury. J Am Coll Cardiol 2007, 50, 1435-1441, doi:10.1016/j.jacc.2007.06.037.

28. van Dalen, E.C.; Raphael, M.F.; Caron, H.N.; Kremer, L.C. Treatment including anthracyclines versus treatment not including anthracyclines for childhood cancer. Cochrane Database Syst Rev 2009, 10.1002/14651858.CD006647.pub2, CD006647, doi:10.1002/14651858.CD006647.pub2.

29. Abdelgawad, I.Y.; Grant, M.K.O.; Zordoky, B.N. Leveraging the Cardio-Protective and Anticancer Properties of Resveratrol in Cardio-Oncology. Nutrients 2019, 11, doi:10.3390/nu11030627.

30. Herrmann, J. Adverse cardiac effects of cancer therapies: cardiotoxicity and arrhythmia. Nat Rev Cardiol 2020, 10.1038/s41569-020-0348-1, doi:10.1038/s41569-020-0348-1.

31. Adams, M.J.; Lipsitz, S.R.; Colan, S.D.; Tarbell, N.J.; Treves, S.T.; Diller, L.; Greenbaum, N.; Mauch, P.; Lipshultz, S.E. Cardiovascular status in long-term survivors of Hodgkin's disease treated with chest radiotherapy. J Clin Oncol 2004, 22, 3139-3148, doi:10.1200/JCO.2004.09.109.

32. Adams, M.J.; Lipshultz, S.E.; Schwartz, C.; Fajardo, L.F.; Coen, V.; Constine, L.S. Radiation-associated cardiovascular disease: manifestations and management. Semin Radiat Oncol 2003, 13, 346-356, doi:10.1016/S1053-4296(03)00026-2.

33. Heo, J.; Jung, H.J.; Noh, O.K.; Kim, L.; Park, J.E. Incidence of Influenza Among Childhood Cancer Survivors in South Korea: A Population-based Retrospective Analysis. In Vivo 2020, 34, 929-933, doi:10.21873/invivo.11860.

34. Heo, J.; Chun, M.; Oh, Y.T.; Noh, O.K.; Kim, L. Influenza Among Breast Cancer Survivors in South Korea: A Nationwide Population-Based Study. In Vivo 2017, 31, 967-972, doi:10.21873/invivo.11155. 
35. Ojha, R.P.; Offutt-Powell, T.N.; Gurney, J.G. Influenza vaccination coverage among adult survivors of pediatric cancer. Am J Prev Med 2014, 46, 552-558, doi:10.1016/j.amepre.2014.01.007.

36. Bansal, N.; Amdani, S.M.; Hutchins, K.K.; Lipshultz, S.E. Cardiovascular disease in survivors of childhood cancer. Curr Opin Pediatr 2018, 30, 628-638, doi:10.1097/MOP.0000000000000675.

37. Feijen, E.A.M.; Leisenring, W.M.; Stratton, K.L.; Ness, K.K.; van der Pal, H.J.H.; van Dalen, E.C.; Armstrong, G.T.; Aune, G.J.; Green, D.M.; Hudson, M.M., et al. Derivation of Anthracycline and Anthraquinone Equivalence Ratios to Doxorubicin for Late-Onset Cardiotoxicity. JAMA Oncol 2019, 5, 864-871, doi:10.1001/jamaoncol.2018.6634.

38. Nysom, K.; Holm, K.; Lipsitz, S.R.; Mone, S.M.; Colan, S.D.; Orav, E.J.; Sallan, S.E.; Olsen, J.H.; Hertz, H.; Jacobsen, J.R., et al. Relationship between cumulative anthracycline dose and late cardiotoxicity in childhood acute lymphoblastic leukemia. J Clin Oncol 1998, 16, 545-550, doi:10.1200/JCO.1998.16.2.545.

39. Leger, K.; Slone, T.; Lemler, M.; Leonard, D.; Cochran, C.; Bowman, W.P.; Bashore, L.; Winick, N. Subclinical cardiotoxicity in childhood cancer survivors exposed to very low dose anthracycline therapy. Pediatr Blood Cancer 2015, 62, 123-127, doi:10.1002/pbc.25206.

40. Vandecruys, E.; Mondelaers, V.; De Wolf, D.; Benoit, Y.; Suys, B. Late cardiotoxicity after low dose of anthracycline therapy for acute lymphoblastic leukemia in childhood. J Cancer Surviv 2012, 6, 95-101, doi:10.1007/s11764-011-0186-6.

41. Yeh, E.T.; Vejpongsa, P. Subclinical Cardiotoxicity Associated With Cancer Therapy: Early Detection and Future Directions. J Am Coll Cardiol 2015, 65, 2523-2525, doi:10.1016/j.jacc.2015.04.012.

42. Neilan, T.G.; Blake, S.L.; Ichinose, F.; Raher, M.J.; Buys, E.S.; Jassal, D.S.; Furutani, E.; Perez-Sanz, T.M.; Graveline, A.; Janssens, S.P., et al. Disruption of nitric oxide synthase 3 protects against the cardiac injury, dysfunction, and mortality induced by doxorubicin. Circulation 2007, 116, 506-514, doi:CIRCULATIONAHA.106.652339 [pii]

10.1161/CIRCULATIONAHA.106.652339.

43. Riad, A.; Bien, S.; Westermann, D.; Becher, P.M.; Loya, K.; Landmesser, U.; Kroemer, H.K.; Schultheiss, H.P.; Tschope, C. Pretreatment with statin attenuates the cardiotoxicity of Doxorubicin in mice. Cancer Res 2009, 69, 695-699, doi:69/2/695 [pii]

\subsection{8/0008-5472.CAN-08-3076.}

44. Zhang, Y.W.; Shi, J.; Li, Y.J.; Wei, L. Cardiomyocyte death in doxorubicin-induced cardiotoxicity. Arch Immunol Ther Exp (Warsz) 2009, 57, 435-445, doi:10.1007/s00005-009-0051-8.

45. Baar, M.P.; Brandt, R.M.C.; Putavet, D.A.; Klein, J.D.D.; Derks, K.W.J.; Bourgeois, B.R.M.; Stryeck, S.; Rijksen, Y.; van Willigenburg, H.; Feijtel, D.A., 
et al. Targeted Apoptosis of Senescent Cells Restores Tissue Homeostasis in Response to Chemotoxicity and Aging. Cell 2017, 169, 132-147 e116, doi:10.1016/j.cell.2017.02.031.

46. Demaria, M.; O'Leary, M.N.; Chang, J.; Shao, L.; Liu, S.; Alimirah, F.; Koenig, K.; Le, C.; Mitin, N.; Deal, A.M., et al. Cellular Senescence Promotes Adverse Effects of Chemotherapy and Cancer Relapse. Cancer Discov 2017, 7, 165-176, doi:10.1158/2159-8290.CD-16-0241.

47. Piegari, E.; De Angelis, A.; Cappetta, D.; Russo, R.; Esposito, G.; Costantino, S.; Graiani, G.; Frati, C.; Prezioso, L.; Berrino, L., et al. Doxorubicin induces senescence and impairs function of human cardiac progenitor cells. Basic Res Cardiol 2013, 108, 334, doi:10.1007/s00395-013-0334-4.

48. Wallace, K.B. Doxorubicin-induced cardiac mitochondrionopathy. Pharmacol Toxicol 2003, 93, 105-115.

49. Grant, M.K.O.; Abdelgawad, I.Y.; Lewis, C.A.; Zordoky, B.N. Sexual Dimorphism in Doxorubicin-induced Systemic Inflammation: Implications for Hepatic Cytochrome P450 Regulation. Int J Mol Sci 2020, 21, doi:10.3390/ijms21041279.

50. Tokarska-Schlattner, M.; Wallimann, T.; Schlattner, U. Alterations in myocardial energy metabolism induced by the anti-cancer drug doxorubicin. C R Biol 2006, 329, 657-668, doi:S1631-0691(06)00125-9 [pii]

10.1016/j.crvi.2005.08.007.

51. Tokarska-Schlattner, M.; Zaugg, M.; Zuppinger, C.; Wallimann, T.; Schlattner, U. New insights into doxorubicin-induced cardiotoxicity: the critical role of cellular energetics. J Mol Cell Cardiol 2006, 41, 389-405, doi:S0022-2828(06)00620-1 [pii]

10.1016/j.yjmcc.2006.06.009.

52. Maslov, M.Y.; Chacko, V.P.; Hirsch, G.A.; Akki, A.; Leppo, M.K.; Steenbergen, C.; Weiss, R.G. Reduced in vivo high-energy phosphates precede adriamycin-induced cardiac dysfunction. Am J Physiol Heart Circ Physiol 2010, 299, H332-337, doi:ajpheart.00727.2009 [pii]

10.1152/ajpheart.00727.2009.

53. Okur, A.; Karadeniz, C.; Ozhan Oktar, S.; Pinarli, F.G.; Aral, A.; Oguz, A. Assessment of brachial artery reactivity, carotid intima-media thickness, and adhesion molecules in pediatric solid tumor patients treated with anthracyclines. Pediatr Hematol Oncol 2016, 33, 178-185, doi:10.3109/08880018.2016.1146375.

54. Chow, A.Y.; Chin, C.; Dahl, G.; Rosenthal, D.N. Anthracyclines cause endothelial injury in pediatric cancer patients: a pilot study. J Clin Oncol 2006, 24, 925-928, doi:10.1200/JCO.2005.03.5956.

55. Krystal, J.I.; Reppucci, M.; Mayr, T.; Fish, J.D.; Sethna, C. Arterial stiffness in childhood cancer survivors. Pediatr Blood Cancer 2015, 62, 1832-1837, doi:10.1002/pbc.25547. 
56. Jenei, Z.; Bardi, E.; Magyar, M.T.; Horvath, A.; Paragh, G.; Kiss, C. Anthracycline causes impaired vascular endothelial function and aortic stiffness in long term survivors of childhood cancer. Pathol Oncol Res 2013, 19, 375-383, doi:10.1007/s12253-012-9589-6.

57. Chu, T.F.; Rupnick, M.A.; Kerkela, R.; Dallabrida, S.M.; Zurakowski, D.; Nguyen, L.; Woulfe, K.; Pravda, E.; Cassiola, F.; Desai, J., et al. Cardiotoxicity associated with tyrosine kinase inhibitor sunitinib. Lancet 2007, 370, 2011-2019, doi:10.1016/S0140-6736(07)61865-0.

58. Cooper, S.L.; Sandhu, H.; Hussain, A.; Mee, C.; Maddock, H. Involvement of mitogen activated kinase kinase 7 intracellular signalling pathway in Sunitinib-induced cardiotoxicity. Toxicology 2018, 394, 72-83, doi:10.1016/j.tox.2017.12.005.

59. Korashy, H.M.; Al-Suwayeh, H.A.; Maayah, Z.H.; Ansari, M.A.; Ahmad, S.F.; Bakheet, S.A. Mitogen-activated protein kinases pathways mediate the sunitinib-induced hypertrophy in rat cardiomyocyte H9c2 cells. Cardiovasc Toxicol 2015, 15, 41-51, doi:10.1007/s12012-014-9266-y.

60. Kerkela, R.; Woulfe, K.C.; Durand, J.B.; Vagnozzi, R.; Kramer, D.; Chu, T.F.; Beahm, C.; Chen, M.H.; Force, T. Sunitinib-induced cardiotoxicity is mediated by off-target inhibition of AMP-activated protein kinase. Clin Transl Sci 2009, 2, 15-25, doi:10.1111/j.1752-8062.2008.00090.x.

61. Nemeth, B.T.; Varga, Z.V.; Wu, W.J.; Pacher, P. Trastuzumab cardiotoxicity: from clinical trials to experimental studies. Br J Pharmacol 2017, 174, 3727-3748, doi:10.1111/bph.13643.

62. Ewer, M.S.; Ewer, S.M. Trastuzumab Cardiotoxicity After Anthracycline Exposure Constitutes a Complex and Clinically Important Entity. JACC Heart Fail 2019, 7, 805-807, doi:10.1016/j.jchf.2019.04.012.

63. Bajwa, R.; Cheema, A.; Khan, T.; Amirpour, A.; Paul, A.; Chaughtai, S.; Patel, S.; Patel, T.; Bramson, J.; Gupta, V., et al. Adverse Effects of Immune Checkpoint Inhibitors (Programmed Death-1 Inhibitors and Cytotoxic T-Lymphocyte-Associated Protein-4 Inhibitors): Results of a Retrospective Study. J Clin Med Res 2019, 11, 225-236, doi:10.14740/jocmr3750.

64. Ayash, L.J.; Wright, J.E.; Tretyakov, O.; Gonin, R.; Elias, A.; Wheeler, C.; Eder, J.P.; Rosowsky, A.; Antman, K.; Frei, E., 3rd. Cyclophosphamide pharmacokinetics: correlation with cardiac toxicity and tumor response. $J$ Clin Oncol 1992, 10, 995-1000, doi:10.1200/JCO.1992.10.6.995.

65. Tiersten, A.; Wo, J.; Jacobson, C.; Weitzman, A.; Horwich, T.; Hesdorffer, C.; Savage, D.; Troxel, A. Cardiac toxicity observed in association with high-dose cyclophosphamide-based chemotherapy for metastatic breast cancer. Breast 2004, 13, 341-346, doi:10.1016/j.breast.2004.02.007.

66. Nagi, M.N.; Al-Shabanah, O.A.; Hafez, M.M.; Sayed-Ahmed, M.M. Thymoquinone supplementation attenuates cyclophosphamide-induced cardiotoxicity in rats. J Biochem Mol Toxicol 2011, 25, 135-142, doi:10.1002/jbt.20369. 
67. Ma, H.; Jones, K.R.; Guo, R.; Xu, P.; Shen, Y.; Ren, J. Cisplatin compromises myocardial contractile function and mitochondrial ultrastructure: role of endoplasmic reticulum stress. Clin Exp Pharmacol Physiol 2010, 37, 460-465, doi:10.1111/j.1440-1681.2009.05323.x.

68. Wang, J.; He, D.; Zhang, Q.; Han, Y.; Jin, S.; Qi, F. Resveratrol protects against Cisplatin-induced cardiotoxicity by alleviating oxidative damage. Cancer Biother Radiopharm 2009, 24, 675-680, doi:10.1089/cbr.2009.0679.

69. Tapio, S. Pathology and biology of radiation-induced cardiac disease. J Radiat Res 2016, 57, 439-448, doi:10.1093/jrr/rrw064.

70. Mansour, H.H.; Tawfik, S.S. Early treatment of radiation-induced heart damage in rats by caffeic acid phenethyl ester. Eur J Pharmacol 2012, 692, 46-51, doi:10.1016/j.ejphar.2012.06.037.

71. Pradeep, K.; Ko, K.C.; Choi, M.H.; Kang, J.A.; Chung, Y.J.; Park, S.H. Protective effect of hesperidin, a citrus flavanoglycone, against gamma-radiation-induced tissue damage in Sprague-Dawley rats. J Med Food 2012, 15, 419-427, doi:10.1089/jmf.2011.1737.

72. Panganiban, R.A.; Mungunsukh, O.; Day, R.M. X-irradiation induces ER stress, apoptosis, and senescence in pulmonary artery endothelial cells. Int J Radiat Biol 2013, 89, 656-667, doi:10.3109/09553002.2012.711502.

73. Michalowski, A.S. On radiation damage to normal tissues and its treatment. II. Anti-inflammatory drugs. Acta Oncol 1994, 33, 139-157.

74. Meeren, A.V.; Bertho, J.M.; Vandamme, M.; Gaugler, M.H. Ionizing radiation enhances IL-6 and IL-8 production by human endothelial cells. Mediators Inflamm 1997, 6, 185-193, doi:10.1080/09629359791677.

75. Suzuki, K.; Mori, I.; Nakayama, Y.; Miyakoda, M.; Kodama, S.; Watanabe, M. Radiation-induced senescence-like growth arrest requires TP53 function but not telomere shortening. Radiat Res 2001, 155, 248-253.

76. Clerkin, K.J.; Fried, J.A.; Raikhelkar, J.; Sayer, G.; Griffin, J.M.; Masoumi, A.; Jain, S.S.; Burkhoff, D.; Kumaraiah, D.; Rabbani, L., et al. Coronavirus Disease 2019 (COVID-19) and Cardiovascular Disease. Circulation 2020, 10.1161/CIRCULATIONAHA.120.046941, doi:10.1161/CIRCULATIONAHA.120.046941.

77. Wang, D.; Hu, B.; Hu, C.; Zhu, F.; Liu, X.; Zhang, J.; Wang, B.; Xiang, H.; Cheng, Z.; Xiong, Y., et al. Clinical Characteristics of 138 Hospitalized Patients With 2019 Novel Coronavirus-Infected Pneumonia in Wuhan, China. JAMA 2020, 10.1001/jama.2020.1585, doi:10.1001/jama.2020.1585.

78. Zheng, Y.Y.; Ma, Y.T.; Zhang, J.Y.; Xie, X. COVID-19 and the cardiovascular system. Nat Rev Cardiol 2020, 10.1038/s41569-020-0360-5, doi:10.1038/s41569-020-0360-5.

79. Zhou, F.; Yu, T.; Du, R.; Fan, G.; Liu, Y.; Liu, Z.; Xiang, J.; Wang, Y.; Song, B.; $\mathrm{Gu}, \mathrm{X}_{.}$, et al. Clinical course and risk factors for mortality of adult inpatients with COVID-19 in Wuhan, China: a retrospective cohort study. Lancet 2020, 395, 1054-1062, doi:10.1016/S0140-6736(20)30566-3. 
80. Hu, H.; Ma, F.; Wei, X.; Fang, Y. Coronavirus fulminant myocarditis saved with glucocorticoid and human immunoglobulin. Eur Heart J 2020, 10.1093/eurheartj/ehaa190, doi:10.1093/eurheartj/ehaa190.

81. Armstrong, G.T.; Oeffinger, K.C.; Chen, Y.; Kawashima, T.; Yasui, Y.; Leisenring, W.; Stovall, M.; Chow, E.J.; Sklar, C.A.; Mulrooney, D.A., et al. Modifiable risk factors and major cardiac events among adult survivors of childhood cancer. J Clin Oncol 2013, 31, 3673-3680, doi:10.1200/JCO.2013.49.3205.

82. Chait-Rubinek, L.; Mariani, J.A.; Goroncy, N.; Herschtal, A.; Wheeler, G.C.; Dwyer, M.K.; Seymour, J.F.; Campbell, B.A. A Retrospective Evaluation of Risk of Peripartum Cardiac Dysfunction in Survivors of Childhood, Adolescent and Young Adult Malignancies. Cancers (Basel) 2019, 11, doi:10.3390/cancers11081046.

83. Cowgill, J.A.; Francis, S.A.; Sawyer, D.B. Anthracycline and Peripartum Cardiomyopathies. Circ Res 2019, 124, 1633-1646, doi:10.1161/CIRCRESAHA.119.313577.

84. Hines, M.R.; Mulrooney, D.A.; Hudson, M.M.; Ness, K.K.; Green, D.M.; Howard, S.C.; Krasin, M.; Metzger, M.L. Pregnancy-associated cardiomyopathy in survivors of childhood cancer. J Cancer Surviv 2016, 10, 113-121, doi:10.1007/s11764-015-0457-8.

85. Huang, C.; Zhang, X.; Ramil, J.M.; Rikka, S.; Kim, L.; Lee, Y.; Gude, N.A.; Thistlethwaite, P.A.; Sussman, M.A.; Gottlieb, R.A., et al. Juvenile exposure to anthracyclines impairs cardiac progenitor cell function and vascularization resulting in greater susceptibility to stress-induced myocardial injury in adult mice. Circulation 2010, 121, 675-683, doi:10.1161/CIRCULATIONAHA.109.902221.

86. Matsumura, N.; Zordoky, B.N.; Robertson, I.M.; Hamza, S.M.; Parajuli, N.; Soltys, C.M.; Beker, D.L.; Grant, M.K.; Razzoli, M.; Bartolomucci, A., et al. Co-administration of resveratrol with doxorubicin in young mice attenuates detrimental late-occurring cardiovascular changes. Cardiovasc Res 2018, 114, 1350-1359, doi:10.1093/cvr/cvy064.

87. Huang, C.; Wang, Y.; Li, X.; Ren, L.; Zhao, J.; Hu, Y.; Zhang, L.; Fan, G.; Xu, J.; $\mathrm{Gu}, \mathrm{X}$. , et al. Clinical features of patients infected with 2019 novel coronavirus in Wuhan, China. Lancet 2020, 395, 497-506, doi:10.1016/S0140-6736(20)30183-5.

88. Lippi, G.; Wong, J.; Henry, B.M. Hypertension and its severity or mortality in Coronavirus Disease 2019 (COVID-19): a pooled analysis. Pol Arch Intern Med 2020, 10.20452/pamw.15272, doi:10.20452/pamw.15272.

89. Sargiacomo, C.; Sotgia, F.; Lisanti, M.P. COVID-19 and chronological aging: senolytics and other anti-aging drugs for the treatment or prevention of corona virus infection? Aging (Albany NY) 2020, 10.18632/aging.103001, doi:10.18632/aging.103001.

90. Vatanen, A.; Hou, M.; Huang, T.; Soder, O.; Jahnukainen, T.; Kurimo, M.; Ojala, T.H.; Sarkola, T.; Turanlahti, M.; Saarinen-Pihkala, U.M., et al. Clinical 
and biological markers of premature aging after autologous SCT in childhood cancer. Bone Marrow Transplant 2017, 52, 600-605, doi:10.1038/bmt.2016.334.

91. Krystal, J.I.; Sethna, C.; Fish, J.D. Vascular Aging in Childhood Cancer Survivors. Pediatr Blood Cancer 2015, 62, 2251, doi:10.1002/pbc.25659.

92. Ness, K.K.; Krull, K.R.; Jones, K.E.; Mulrooney, D.A.; Armstrong, G.T.; Green, D.M.; Chemaitilly, W.; Smith, W.A.; Wilson, C.L.; Sklar, C.A., et al. Physiologic frailty as a sign of accelerated aging among adult survivors of childhood cancer: a report from the St Jude Lifetime cohort study. J Clin Oncol 2013, 31, 4496-4503, doi:10.1200/JCO.2013.52.2268.

93. Lowe, D.; Raj, K. Premature aging induced by radiation exhibits pro-atherosclerotic effects mediated by epigenetic activation of CD44 expression. Aging Cell 2014, 13, 900-910, doi:10.1111/acel.12253.

94. Rugbjerg, K.; Olsen, J.H. Radiation Therapy for Treatment of Adolescent and Young Adult Hodgkin Lymphoma and Risk for Cardiovascular Disease and Cancer. J Adolesc Young Adult Oncol 2019, 8, 1-8, doi:10.1089/jayao.2018.0060.

95. Toth, P.; Tarantini, S.; Springo, Z.; Tucsek, Z.; Gautam, T.; Giles, C.B.; Wren, J.D.; Koller, A.; Sonntag, W.E.; Csiszar, A., et al. Aging exacerbates hypertension-induced cerebral microhemorrhages in mice: role of resveratrol treatment in vasoprotection. Aging Cell 2015, 14, 400-408, doi:10.1111/acel.12315.

96. Walaszczyk, A.; Dookun, E.; Redgrave, R.; Tual-Chalot, S.; Victorelli, S.; Spyridopoulos, I.; Owens, A.; Arthur, H.M.; Passos, J.F.; Richardson, G.D. Pharmacological clearance of senescent cells improves survival and recovery in aged mice following acute myocardial infarction. Aging Cell 2019, 18, e12945, doi:10.1111/acel.12945.

97. Wang, Y.; Di, Y.; Ye, J.; Wei, W. Study on the public psychological states and its related factors during the outbreak of coronavirus disease 2019 (COVID-19) in some regions of China. Psychol Health Med 2020, 10.1080/13548506.2020.1746817, 1-10, doi:10.1080/13548506.2020.1746817.

98. Qiu, J.; Shen, B.; Zhao, M.; Wang, Z.; Xie, B.; Xu, Y. A nationwide survey of psychological distress among Chinese people in the COVID-19 epidemic: implications and policy recommendations. Gen Psychiatr 2020, 33, e100213, doi:10.1136/gpsych-2020-100213.

99. Jung, S.J.; Jun, J.Y. Mental Health and Psychological Intervention Amid COVID-19 Outbreak: Perspectives from South Korea. Yonsei Med J 2020, 61, 271-272, doi:10.3349/ymj.2020.61.4.271.

100. Bo, H.X.; Li, W.; Yang, Y.; Wang, Y.; Zhang, Q.; Cheung, T.; Wu, X.; Xiang, Y.T. Posttraumatic stress symptoms and attitude toward crisis mental health services among clinically stable patients with COVID-19 in China. Psychol Med 2020, 10.1017/S0033291720000999, 1-7, doi:10.1017/S0033291720000999.

101. Nguyen, H.C.; Nguyen, M.H.; Do, B.N.; Tran, C.Q.; Nguyen, T.T.P.; Pham, K.M.; Pham, L.V.; Tran, K.V.; Duong, T.T.; Tran, T.V., et al. People with Suspected COVID-19 Symptoms Were More Likely Depressed and Had 
Lower Health-Related Quality of Life: The Potential Benefit of Health Literacy. J Clin Med 2020, 9, doi:10.3390/jcm9040965.

102. Cao, W.; Fang, Z.; Hou, G.; Han, M.; Xu, X.; Dong, J.; Zheng, J. The psychological impact of the COVID-19 epidemic on college students in China. Psychiatry Res 2020, 287, 112934, doi:10.1016/j.psychres.2020.112934.

103. Dong, M.; Zheng, J. Letter to the editor: Headline stress disorder caused by Netnews during the outbreak of COVID-19. Health Expect 2020, 23, 259-260, doi:10.1111/hex.13055.

104. Rozanski, A.; Blumenthal, J.A.; Kaplan, J. Impact of psychological factors on the pathogenesis of cardiovascular disease and implications for therapy. Circulation 1999, 99, 2192-2217.

105. Ford, D.E.; Mead, L.A.; Chang, P.P.; Cooper-Patrick, L.; Wang, N.Y.; Klag, M.J. Depression is a risk factor for coronary artery disease in men: the precursors study. Arch Intern Med 1998, 158, 1422-1426.

106. Kivimaki, M.; Virtanen, M.; Elovainio, M.; Kouvonen, A.; Vaananen, A.; Vahtera, J. Work stress in the etiology of coronary heart disease--a meta-analysis. Scand J Work Environ Health 2006, 32, 431-442.

107. Kamphuis, M.H.; Kalmijn, S.; Tijhuis, M.A.; Geerlings, M.I.; Giampaoli, S.; Nissinen, A.; Grobbee, D.E.; Kromhout, D. Depressive symptoms as risk factor of cardiovascular mortality in older European men: the Finland, Italy and Netherlands Elderly (FINE) study. Eur J Cardiovasc Prev Rehabil 2006, 13, 199-206, doi:10.1097/01.hjr.0000188242.64590.92.

108. Brinkman, T.M.; Li, C.; Vannatta, K.; Marchak, J.G.; Lai, J.S.; Prasad, P.K.; Kimberg, C.; Vuotto, S.; Di, C.; Srivastava, D., et al. Behavioral, Social, and Emotional Symptom Comorbidities and Profiles in Adolescent Survivors of Childhood Cancer: A Report From the Childhood Cancer Survivor Study. J Clin Oncol 2016, 34, 3417-3425, doi:10.1200/JCO.2016.66.4789.

109. Prasad, P.K.; Hardy, K.K.; Zhang, N.; Edelstein, K.; Srivastava, D.; Zeltzer, L.; Stovall, M.; Seibel, N.L.; Leisenring, W.; Armstrong, G.T., et al. Psychosocial and Neurocognitive Outcomes in Adult Survivors of Adolescent and Early Young Adult Cancer: A Report From the Childhood Cancer Survivor Study. J Clin Oncol 2015, 33, 2545-2552, doi:10.1200/JCO.2014.57.7528.

110. Johannsdottir, I.M.R.; Hamre, H.; Fossa, S.D.; Loge, J.H.; Drolsum, L.; Lund, M.B.; Nordsletten, L.; Kiserud, C. Adverse Health Outcomes and Associations with Self-Reported General Health in Childhood Lymphoma Survivors. J Adolesc Young Adult Oncol 2017, 6, 470-476, doi:10.1089/jayao.2017.0018.

111. Tremolada, M.; Bonichini, S.; Basso, G.; Pillon, M. Post-traumatic Stress Symptoms and Post-traumatic Growth in 223 Childhood Cancer Survivors: Predictive Risk Factors. Front Psychol 2016, 7, 287, doi:10.3389/fpsyg.2016.00287.

112. Kuba, K.; Esser, P.; Mehnert, A.; Hinz, A.; Johansen, C.; Lordick, F.; Gotze, H. Risk for depression and anxiety in long-term survivors of hematologic cancer. Health Psychol 2019, 38, 187-195, doi:10.1037/hea0000713. 
113. Ehrhardt, M.J.; Mulrooney, D.A.; Li, C.; Baassiri, M.J.; Bjornard, K.; Sandlund, J.T.; Brinkman, T.M.; Huang, I.C.; Srivastava, D.K.; Ness, K.K., et al. Neurocognitive, psychosocial, and quality-of-life outcomes in adult survivors of childhood non-Hodgkin lymphoma. Cancer 2018, 124, 417-425, doi:10.1002/cncr.31019.

114. Schoormans, D.; Pedersen, S.S.; Dalton, S.; Rottmann, N.; Poll-Franse, L.v.d. Cardiovascular co-morbidity in cancer patients: the role of psychological distress. Cardio-Oncology 2016, 2, 9, doi:10.1186/s40959-016-0019-x.

115. Vuotto, S.C.; Krull, K.R.; Li, C.; Oeffinger, K.C.; Green, D.M.; Patel, S.K.; Srivastava, D.; Stovall, M.; Ness, K.K.; Armstrong, G.T., et al. Impact of chronic disease on emotional distress in adult survivors of childhood cancer: A report from the Childhood Cancer Survivor Study. Cancer 2017, 123, 521-528, doi:10.1002/cncr.30348.

116. Schoormans, D.; van de Poll-Franse, L.; Vissers, P.; van Herk-Sukel, M.P.P.; Pedersen, S.S.; Rottmann, N.; Horsbol, T.; Dalton, S.; Denollet, J.

Pharmaceutically treated anxiety but not depression prior to cancer diagnosis predicts the onset of cardiovascular disease among breast cancer survivors. Breast Cancer Res Treat 2017, 166, 259-266, doi:10.1007/s10549-017-4387-1.

117. Rundle, A.G.; Park, Y.; Herbstman, J.B.; Kinsey, E.W.; Wang, Y.C. COVID-19 Related School Closings and Risk of Weight Gain Among Children. Obesity (Silver Spring) 2020, 10.1002/oby.22813, doi:10.1002/oby.22813.

118. Dietz, W.; Santos-Burgoa, C. Obesity and its Implications for COVID-19 Mortality. Obesity (Silver Spring) 2020, 10.1002/oby.22818, doi:10.1002/oby.22818.

119. Glenn, B.A.; Hamilton, A.S.; Nonzee, N.J.; Maxwell, A.E.; Crespi, C.M.; Ryerson, A.B.; Chang, L.C.; Deapen, D.; Bastani, R. Obesity, physical activity, and dietary behaviors in an ethnically-diverse sample of cancer survivors with early onset disease. J Psychosoc Oncol 2018, 36, 418-436, doi:10.1080/07347332.2018.1448031.

120. Murphy, B.R.; Raber, M.P.; Crawford, K.D.; Grasse, L.; Wartenberg, L.; Wu, J.; Dibaj, S.S.; Chandra, J. High Rates of Obesity at Presentation Persist into Survivorship across Childhood Cancer Types. Child Obes 2020, 10.1089/chi.2019.0180, doi:10.1089/chi.2019.0180.

121. Pluimakers, V.G.; van Waas, M.; Neggers, S.; van den Heuvel-Eibrink, M.M. Metabolic syndrome as cardiovascular risk factor in childhood cancer survivors. Crit Rev Oncol Hematol 2019, 133, 129-141, doi:10.1016/j.critrevonc.2018.10.010. 